\title{
ELECTRO MECHANICAL SPLIT PAD DISC BRAKE USING SOLENOID VALVE
}

\author{
Jatin Bhandari ${ }^{1}$, Ankit Kandpal ${ }^{2}$ \\ ${ }^{I}$ UG scholar, Mechanical Engineering Department, College of Technology, Pantnagar, Uttrakhand, India \\ ${ }^{2} U G$ scholar, Mechanical Engineering Department, College of Technology, Pantnagar, Uttrakhand, India
}

\begin{abstract}
With the advent of new era came the high performance vehicles which runs at an average speed of $80 \mathrm{~km} / \mathrm{hr}$. Braking at higher speeds created problems like high brake shoe wear, false braking and loss of maneuverability. To cope up with the new situations, new braking systems needs to be developed, which are highly refined and automated. We have developed a system that is a solution to the current problem. The system is an amalgamation of electrical and mechanical aspects, hence giving the brakes dual functionality, thus increasing the service life and performance simultaneously.
\end{abstract}

Keywords: A.B.S, caliper, E.B.D., electro-mechanical disc brake, master cylinder, solenoid valve, split brake pad. $* * *$

\section{INTRODUCTION}

Braking system is an integral part of any automobile. Its work is to slow down the vehicle by exerting resistance to its motion. Since the start of the automobile era many revolutionary ideas has been implemented on the vehicles under this department. The main principle is conversion of kinetic energy into heat energy which is further dissipated into the air. Presently the two commonly used systems in automobiles are-

(1) Drum brakes

(2) Disc brakes.

Several new technologies have been discovered in the field of braking system which is a combination of electrical and mechanical system E.g.-A.B.S. (antilock braking system), E.B.D. (electronic brake force distribution system)

This system, unlike the conventional disc brake system comprises of a floating caliper which consists of three split brake pads. The central one being mechanically actuated; and the other two are controlled by solenoid valves, thus making them electrically actuated. The use of three split pads not only increases the performance and the braking efficiency, but also reduces the wear rate and helps in the implementation of A.B.S. functionality to this braking system.

\section{COMPONENTS INVOLVED}

This braking system comprises of the following components

(1) Brake pedal

(2) Master cylinder

(3) Pressure sensor

(4) Brake linings

(5) T-joints

(6) Caliper assembly

(7) Speed sensor

(8) Solenoid valves- $\{2\}$
(9) Pressure release valve

(10) Integrated circuit board

(11) Vehicle battery.

\section{GENERAL OVERVIEW OF THE SYSTEM}

This braking system is an electro-mechanical system with three split brake pads on the same caliper, each having its own brake line to actuate the piston corresponding to each brake pad and two solenoid valve to control the flow of brake fluid to the first and third piston only. There is a pressure sensors mounted on the master cylinder whose output is fed to small circuit of I.C. (integrated circuit). There is a speed sensor on the tire rim whose output is fed to the same I.C. In case of speeds below $50 \mathrm{~km} / \mathrm{hr}$, the output of the pressure sensor is used to control the solenoid valves. In case of soft braking, only the central brake pad actuates and in case of hard braking, all the three brake pads actuates. For speeds greater than $50 \mathrm{~km} / \mathrm{hr}$, the output of the speed sensor is used to control the solenoid valves (all three actuated) and the ABS function of the brake. In case of ABS when the brakes are applied all three brake pads firstly gets actuated and after a certain interval of time the output from the I.C. to solenoid valves leads to closure of solenoid valves hence disengaging first and third brake pad, and ultimately resulting in decrease in the brake force. 


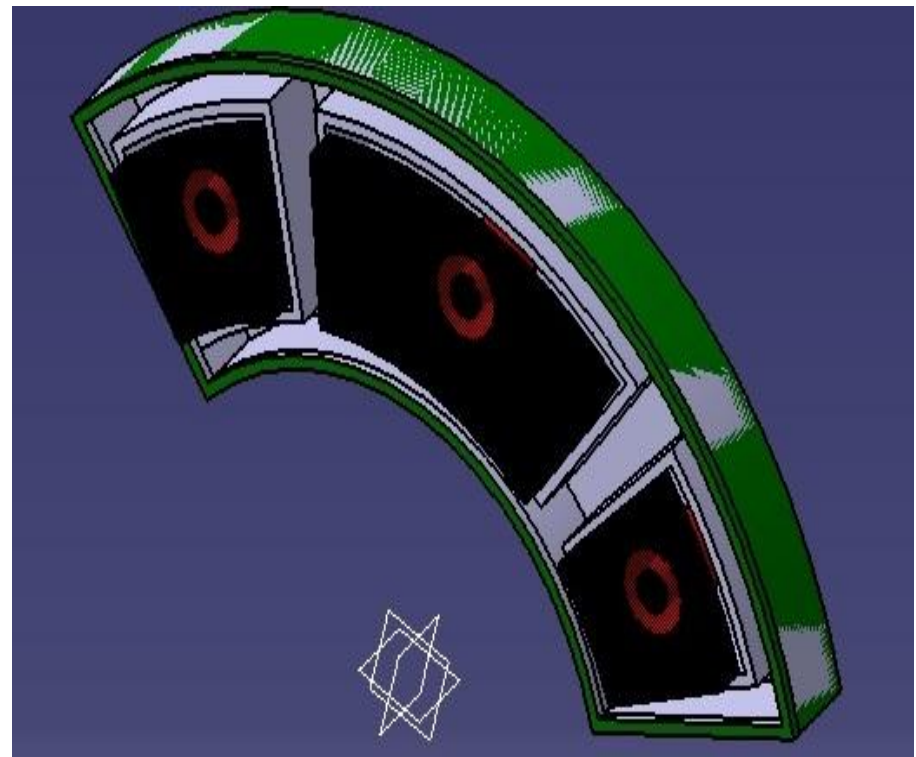

Fig. 1: split brake pad (3-pads)

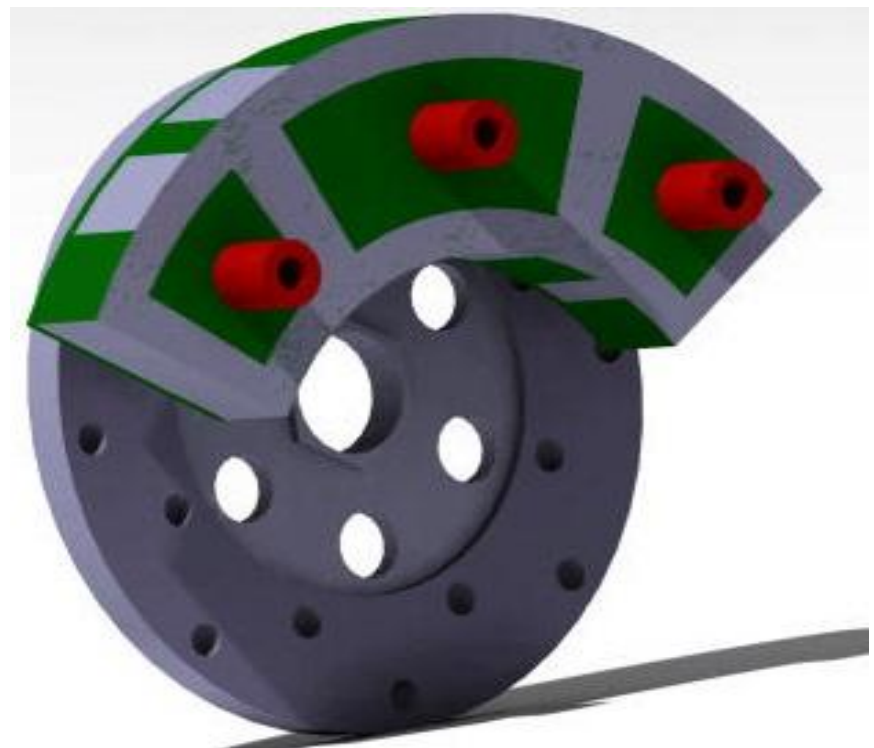

Fig. 2: brake pad and disc assembly.

\section{WORKING OF A.B.S.}

This system also includes A.B.S. which is made to work by the pressure difference in the system itself. There goes a brake line from the mid of solenoid valve and piston in the cylinder to brake fluid reservoir. At the start of the lining there is an electronically controlled pressure release valve. When speed is more than $50 \mathrm{~km} / \mathrm{hr}$ and as the driver applies brakes all the three brake pads actuate and clamps the disc. Now a signal comes from I.C. which makes the solenoid valve to close and just at the same moment the pressure release valve opens making the fluid to flow to the brake fluid reservoir which is at lower pressure as compared to brake line. This makes the piston to retract and disengage. Now after a certain time the solenoid valve opens, pressurizing the piston and again engaging it to the disc. At the same time the pressure release valve is closed by the signal from the I.C. This cycle is repeated till the driver is applying the brakes.

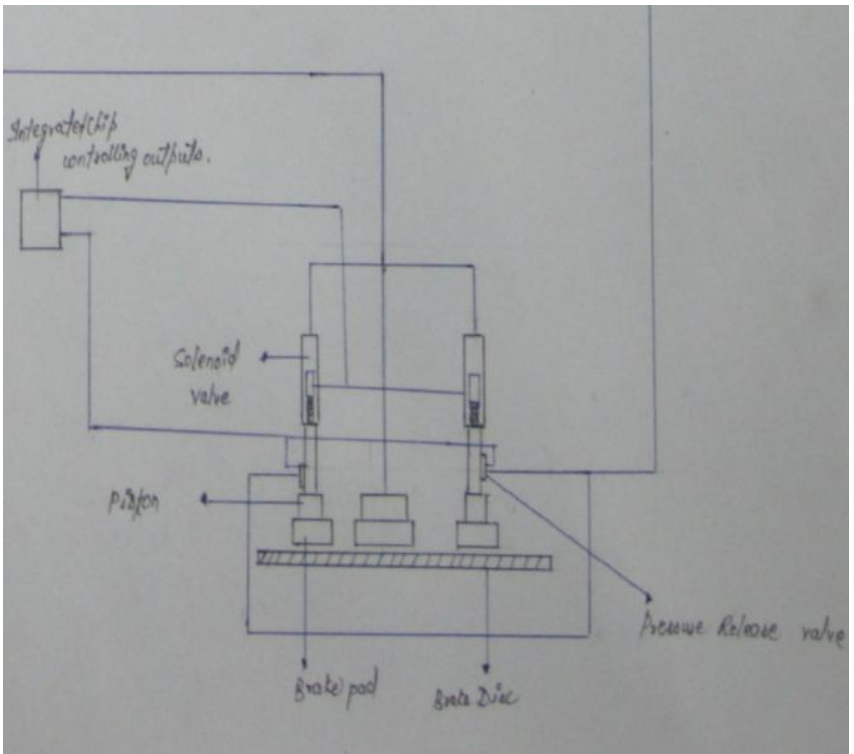

Fig 3: schematic diagram of the system

\section{SIGNIFICANCE/ADVANTAGES OVER} PREVIOUS SYSTEM

1. This system incorporates A.B.S. technology without the use of any microcontroller chip which is expensive and more vulnerable to damage from moisture, heat and mechanical breakdowns.

2. The system results in less wear and tear of the brake pads, hence resulting in longer life of the brakes.

3. Since the system is both electrical as well as mechanical, so if one system fails the other will work hence eliminating the chances of false braking as well as providing dual assurance.

4. The entire system is much more efficient, compact and less expensive as compared to any conventional A.B.S. system available in the market.

\section{CONCLUSION}

We have developed this braking system keeping in mind all the basic requirements that a modern system requires. The electrical system ensures that the brakes are much more efficient and responsive as compared to any conventional mechanical system and the mechanical system acts as a safety if in case the electrical system fails or vice versa.

\section{ACKNOWLEDGEMENTS}

It is indeed a pleasure for us to express our sincere gratitude to those who have always helped us for this research work. We wish to express our gratitude to our parents, whose love and Encouragement have supported us throughout our education. We would also like to thank our seniors, namely Shiromani Raj Pathak sir and Tanuj Joshi sir who helped us with their time and knowledge, whenever needed. 


\section{REFERENCES}

[1]. Singh, Kripal. "Brakes- II" in Automobile Engineering, 3th ed., vol. 1, New Delhi: Standard Publishers Distributors, 2013, pp. 385-397.

[2]. Ganehsan, V. "Non Conventional Engines" in Internal Combustion Engines, 4th ed., New Delhi: Tata McGrawHill, 2012, pp. 649-653.

[3]. "Solenoid and air operated valves" by Asco.

\section{BIOGRAPHIES}

Jatin Bhandari, UG scholar, Mechanical Engineering Department, College Of Technology, Pantnagar, Uttrakhand, India.

Email-jatinb11@gmail.com

Ankit Kandpal, UG scholar, Mechanical Engineering Department, College Of Technology, Pantnagar, Uttrakhand, India.

Email-ankit43312@gmail.com 